\title{
IgM quantification in the cerebrospinal fluid of sleeping sickness patients by a latex card agglutination test
}

\author{
V. Lejon ${ }^{1,2}$, D. Legros ${ }^{3}$, M. Richer ${ }^{4}$, J. A. Ruiz ${ }^{5}$, V. Jamonneau ${ }^{6}$, P. Truc ${ }^{7}$, F. Doua ${ }^{8}$, N. Djé ${ }^{8}$, F. X. N'Siesi ${ }^{9}$, \\ S. Bisser', E. Magnus', I. Wouters', J. Konings' ${ }^{10}$, T. Vervoort ${ }^{10}$, F. Sultan' ' and P. Büscher' \\ 1 Department of Parasitology, Institute of Tropical Medicine, Antwerpen, Belgium \\ 2 Department of Biochemistry, University of Antwerpen, Wilrijk, Belgium \\ 3 EPICENTRE, Paris, France \\ 4 International Medical Corps, Nairobi, Kenya \\ 5 Médecins Sans Frontières-Espagne, Haut Mbomou, République Centrafricaine \\ 6 Institut Pierre Richet, Bouaké, Côte d'Ivoire \\ 7 OCEAC Laboratoire d'Etude de la Chimiosensibilité des Trypanosomes, Yaoundé, Cameroun \\ 8 Projet de Recherches Cliniques sur la Trypanosomiase, Daloa, Côte d'Ivoire \\ 9 Bureau Central de la Trypanosomiase, Bwamanda, R.D. Congo \\ 10 Department of Clinical Sciences, Institute of Tropical Medicine, Antwerpen, Belgium \\ 11 Merck Eurolab, Fontenay-sous-Bois, France
}

Summary An increased IgM concentration in cerebrospinal fluid (CSF), occurring as a consequence of massive intrathecal IgM synthesis, is a marker of interest for diagnosis of the meningo-encephalitic stage in human African trypanosomiasis. However, in current practice, IgM in CSF is not determined because of the lack of a simple and robust test that is applicable in African rural regions where the disease prevails. We describe the development of a sensitive semiquantitative card agglutination test, LATEX/IgM, for IgM quantification in CSF. The test is simple and fast and the lyophilized reagent remains stable even at $45^{\circ} \mathrm{C}$. CSF end-titres obtained with LATEX/IgM parallel the IgM concentrations determined by nephelometry and enzyme-linked immunosorbent assay. Detection of intrathecal IgM synthesis is the most sensitive marker for CNS involvement in sleeping sickness. At a cut-off value of $\geq 8$, the sensitivity and specificity of LATEX/IgM for intrathecal IgM synthesis are 89.4 and $92.7 \%$. As a consequence, patients with LATEX/IgM end-titres $\geq 8$ are likely to have intrathecal IgM synthesis, thus central nervous system involvement and therefore should be treated accordingly. Further studies should concentrate on the relationship between the LATEX/IgM end-titres, presence of intrathecal $\operatorname{IgM}$ synthesis and occurrence of treatment failures in patients treated with pentamidine.

keywords cerebrospinal fluid, IgM, stage determination, latex microspheres, card agglutination, Trypanosoma brucei gambiense, sleeping sickness, intrathecal IgM synthesis

correspondence Veerle Lejon, Department of Parasitology, Institute of Tropical Medicine, Nationalestraat 155, 2000 Antwerpen, Belgium. Fax: +32 3247 6373; E-mail: vlejon@itg.be

\section{Introduction}

Human African trypanosomiasis or sleeping sickness is caused by infection with the protozoan parasites Trypanosoma brucei (T.b.) gambiense or T.b. rhodesiense.

Gambiense sleeping sickness occurs in West to Central subSaharan Africa whereas rhodesiense sleeping sickness is found east of the African rift. The disease is transmitted through the bites of infected tsetse flies. After the infective bite, trypanosomes spread and proliferate in blood and lymph, corresponding to the first or haemo-lymphatic disease stage, followed by central nervous system invasion corresponding to the second or meningo-encephalitic disease stage. As treatment is stage-dependent and treatment of the second stage is not without risks and requires hospitalization (Van Nieuwenhove 1999), differentiation between the disease stages is crucial. Although for stage determination and follow-up the examination of 
V. Lejon et al. IgM quantification in CSF of sleeping sickness patients

cerebrospinal fluid (CSF) on cell count, total protein concentration and presence of trypanosomes is prescribed (WHO 1998), these criteria are not $100 \%$ accurate and in reality seldom combined. As a consequence, stage determination may be incorrect and diagnosis of relapse may be problematic.

The CSF of T.b. gambiense sleeping sickness patients in the meningo-encephalitic stage often contains high concentrations of IgM (Greenwood \& Whittle 1973) originating partially from serum whose $\operatorname{IgM}$ concentration is about five times as high in T.b. gambiense patients as in controls (Bisser et al. 1997), but also, and mainly, from intrathecal IgM synthesis (Bisser et al. 1997, 2002; Lejon et al. 1998a). Such high CSF IgM concentrations are pathognomic for sleeping sickness in the meningoencephalitic stage (Mattern 1968). Furthermore, successful treatment would be followed by a fall in CSF IgM levels (Greenwood \& Whittle 1973), and relapses are characterized by high CSF IgM (Mattern 1967; Whittle et al. 1977). Even today IgM in CSF of sleeping sickness patients is rarely determined because of the lack of a test which is feasible in rural health settings in endemic regions.

Hence, our aim was to develop a simple, robust IgM quantification test for CSF which would not require sophisticated and expensive equipment, such as a nephelometer or enzyme-linked immunosorbent assay (ELISA) equipment, often not available in health centres where the disease is diagnosed. The reagent should be sufficiently stable to allow transport at ambient temperature and longterm storage. We developed a latex card agglutination test for semiquantitative detection of IgM in the CSF (Lejon et al. 1998b), which is easy to perform with only pipettes and a rotator - generally already in use for serological screening by card-agglutination test with stained trypanosomes (CATT) (Magnus et al. 1978). However, batch to batch reactivity variations were observed with this test, inherent to the use of different batches of polyclonal anti-IgM antibodies (personal observation).

Here we describe how coating of monoclonal antibodies on the latex particles by another coupling procedure eliminated batch to batch variation and reduced the reaction time to $5 \mathrm{~min}$. Semi-quantitative IgM detection with LATEX/IgM was compared with quantitative IgM detection by nephelometry. The feasibility of the improved LATEX/IgM test in the field was studied in Sudan and in the Central African Republic. Sensitivity and specificity of LATEX/IgM for intrathecal IgM synthesis, which is the most sensitive marker for neuro-inflammation in sleeping sickness, are investigated and a cut-off for CSF LATEX/IgM end-titre representing intrathecal synthesis is established.

Based on LATEX/IgM results of 937 CSF samples from T.b. gambiense patients from several countries, the relationship of LATEX/IgM end-titres to the cell count and presence of trypanosomes in CSF, which are the conventional WHO criteria for stage determination in sleeping sickness, is shown.

\section{Materials and methods}

\section{Preparation of LATEX/IgM reagent}

One gram of carboxylated polystyrene latex (diameter $0.857 \mu \mathrm{m}, 9 \mu \mathrm{eq}$. COOH, K1-080 red, Estapor France) was washed twice in $40 \mathrm{ml}$ phosphate buffered sodium dodecyl sulphate (SDS) $(0.01 \mathrm{M}, \mathrm{pH} 6,0.01 \%$ SDS) by centrifugation $\left(3400 \mathrm{~g}, 45 \mathrm{~min}, 4^{\circ} \mathrm{C}\right)$. The latex was activated by resuspension of the sediment in $100 \mathrm{ml}$ freshly prepared phosphate buffered SDS containing $10 \mathrm{mg} / \mathrm{ml}$ carbodiimide [1-ethyl-3-(3-dimethylaminopropyl)carbodiimide $\cdot \mathrm{HCl}$, Pierce] and $6 \mathrm{mg} / \mathrm{ml} \mathrm{N}$-hydroxysuccinimide (Sigma). After 15 min of gentle mixing on an end-to-end mixer, the latex was centrifuged and the sediment was washed by resuspension and centrifugation in $40 \mathrm{ml} \mathrm{HCl-SDS}$ solution ( $2 \mathrm{mM} \mathrm{HCl}, 0.01 \%$ SDS) followed by resuspension and centrifugation in $40 \mathrm{ml}$ of $2 \mathrm{mM} \mathrm{HCl}$. The activated sediment was resuspended in $40 \mathrm{ml}$ phosphate buffer (0.02 M, pH 7.4). For coupling, $10 \mathrm{mg}$ of mouse antihuman IgM (clone MH15-1, provided as $2 \mathrm{mg} / \mathrm{ml}$, purified from ascites, in $0.02 \mathrm{M}$ Tris and $0.15 \mathrm{M} \mathrm{NaCl}$, CLB, the Netherlands), diluted in phosphate buffer to a total volume of $10 \mathrm{ml}$, were added. The suspension was stirred overnight at ambient temperature and centrifuged. The sediment was washed three times by centrifugation in $60 \mathrm{ml}$ of phosphate buffer. After the last centrifugation, the latex was resuspended in stabilization buffer $(0.02 \mathrm{M}$ Tris, $\mathrm{pH} 7.4,0.8 \%$ $\mathrm{NaCl}, 1 \% \mathrm{BSA}, 10 \%$ sucrose and $0.1 \% \mathrm{NaN}_{3}$ ) to a $1 \% \mathrm{w} / \mathrm{v}$ latex suspension. The suspension was sonicated on ice (Vibra-cell, $6 \mathrm{~mm}$ probe, amplitude $80,1 \mathrm{~min}$, pulse $3 \mathrm{~s}$, $9 \mathrm{~W}$ output) and monodispersity was checked microscopically (400× magnification). Aliquots containing $10 \mathrm{mg}$ of sensitized latex were dispensed in penicillin vials, snapfrozen in liquid nitrogen and lyophilized with the following temperature settings: $24 \mathrm{~h}$ at $-30{ }^{\circ} \mathrm{C}, 7 \mathrm{~h}$ at $0{ }^{\circ} \mathrm{C}$ and $24 \mathrm{~h}$ at $25^{\circ} \mathrm{C}$. Afterwards the vials were flushed with nitrogen gas and stoppered.

\section{LATEX/IgM test protocol}

Lyophilized latex reagent was resuspended with $1 \mathrm{ml}$ phosphate buffered saline (PBS) $(0.01 \mathrm{M}, \mathrm{pH} 7.4)$ supplemented with $5 \mathrm{mg} / \mathrm{l}$ phenol red for colour contrast.

Twofold serial dilutions of CSF were prepared in the same buffer. On the reaction zone of a test card (white reaction zones with a diameter of $1.5 \mathrm{~cm}), 20 \mu \mathrm{l}$ of latex reagent 
V. Lejon et al. IgM quantification in CSF of sleeping sickness patients

were mixed with $20 \mu \mathrm{l}$ of diluted or undiluted CSF and spread over the reaction zone. The card was rocked on a horizontal rotator (eccentric deviation $12 \mathrm{~mm}$ ) at $70 \mathrm{rpm}$. After $5 \mathrm{~min}$, the degree of agglutination was scored. Invisible or hardly visible agglutination was considered negative, visible up to maximal agglutination was considered positive. The end-titre of a CSF sample, defined as the highest dilution still yielding a positive result, was determined. When the CSF reacted undiluted, but no agglutination was observed in the 1:2 dilution, an end-titre of 1 was given. If no agglutination was obtained even with undiluted CSF, an end-titre of 0 was assigned.

\section{Total IgM and albumin concentration in serum and CSF by nephelometry and ELISA}

The IgM and albumin concentration in serum and CSF was determined by nephelometry (BN100, Dade Behring). In samples with an IgM concentration below the detection limit of nephelometry ( $4 \mathrm{mg} / \mathrm{l}), \operatorname{IgM}$ was measured by a sandwich ELISA. Briefly, microplates were coated overnight with mouse antihuman IgM (CLB, the Netherlands), control wells received PBS. After blocking with a skimmed milk solution, the plates were incubated with CSF (twofold dilutions of 1:4-1:32 in PBS-Blotto), a standard (CSF containing $20 \mathrm{mg} / \mathrm{lgM}$, diluted 1:40-1:5120) and a control (CSF containing $24 \mathrm{mg} / \mathrm{l}$ IgM, diluted 1:40-1:320). Then the wells were filled with rabbit antihuman IgM peroxidase (DAKO, Denmark). Plates were developed using a commercial ABTS solution (Boehringer). The optical density was read at $415 \mathrm{~nm}$ (Multiskan RC Version 6.0, Labsystems) and the IgM concentrations in the CSF samples and the control were interpolated from the standard curve using the four-parameter algorithm provided with the software (Genesis Lite) of the reader.

Intra-assay variability, batch to batch variation and stability of the LATEX/IgM reagent

In order to test intra-assay variability of the reagent, the end-titres of two CSF samples were determined 20 consecutive times using the same vial of LATEX/IgM reagent. Batch to batch variation and stability of the reagent were checked with a set of five reference human serum samples, originating from sleeping sickness patients (R1-3), and normal controls (R4 and 5). These sera were conserved in capillaries of $20 \mu \mathrm{l}$ at $-80^{\circ} \mathrm{C}$, and for each experiment, a new aliquot was used. Batch to batch variation was tested with LATEX/IgM reagent produced on seven different dates, using two different batches of mouse antihuman IgM for coupling onto the particles. Stability of the reagent was assessed after storage of
LATEX/IgM reagent (batch 16/06/99) at 4 and $37-45^{\circ} \mathrm{C}$ for up to 31 months. After 0 (immediately after lyophilization), 35, 92, 183, 289, 406, 497, 727 and 938 days, the reagent was tested.

For these experiments, a maximal variation in end-titre of 1 dilution factor, which can occur as a consequence of different interpretation of doubtful reactions, was considered acceptable.

\section{Serum and CSF samples}

All serum and CSF samples from sleeping sickness patients used for this study were collected during routine diagnostic activities. On blood, these include serological (antibody detection in blood or serum by CATT; Magnus et al. 1978) and parasitological examination (wet blood film, thick blood film, microhematocrite centrifugation or mini-anion exchange centrifugation technique). CSF was examined for stage determination of the disease (cell count and detection of trypanosomes) (Van Meirvenne 1999). No systematic screening for other infections or other neuro-inflammatory diseases in these patients was performed. The origin of the samples is specified for each experiment. No control CSF samples of nonsleeping sickness patients from endemic regions were available.

Based on CSF cell count and presence of trypanosomes, four patient groups were defined: a group with $0-5$ cells $/ \mu \mathrm{l}$ and no trypanosomes in the CSF (first stage patients), a group with 6-20 cells/ $\mu$ l and no trypanosomes in the CSF (early second stage patients), a group with $\leq 20$ cells/ $\mu$ l and trypanosomes in CSF (another early second stage group) and a group with $>20$ cells/ $\mu$ l or trypanosomes in the CSF (second stage patients).

\section{Comparison between CSF end-titre in LATEX/IgM and the $\operatorname{IgM}$ concentration}

The IgM concentrations of CSF samples from 435 T.b. gambiense patients before treatment, originating from Central-West Côte d'Ivoire (102 samples) and from Arua district, Northern Uganda (333 samples), were determined. Samples were grouped according to their LATEX/IgM endtitres and the mean IgM concentration for each group was calculated. Differences between the groups, mean IgM concentrations were assessed by ANOVA statistics (Pagano \& Gauvreau 2000).

\section{Intrathecal IgM synthesis and determination of a LATEX/IgM cut-off end-titre}

We calculated the intrathecal fraction of 93 patients from Côte d'Ivoire and 205 patients from Northern Uganda, 
V. Lejon et al. IgM quantification in CSF of sleeping sickness patients

whose complete serum and CSF albumin and IgM data were available. Twenty-eight patients had $0-5$ cells $/ \mu$ and no trypanosomes in CSF, 54 patients had $6-20$ cells $/ \mu$ l and no trypanosomes in CSF, 43 patients had $\leq 20$ cells $/ \mu \mathrm{l}$ and trypanosomes in CSF and 173 patients had $>20$ cells $/ \mu$ l. Blood-CSF barrier function was evaluated using the CSF/ serum albumin quotient, $Q_{\text {Alb }}$. The age related upper reference limits for $Q_{\mathrm{Alb}}$ are $5 \times 10^{-3}$ (up to 15 years), $6.5 \times 10^{-3}$ (up to 40 years) and $8 \times 10^{-3}$ (up to 60 years) (Reiber \& Felgenhauer 1987). For each CSF/serum pair the maximum IgM quotient $\left[Q_{\mathrm{Lim}}(\mathrm{IgM})\right]$ in absence of intrathecal immunoglobulin synthesis was calculated using the formula

$$
Q_{\mathrm{Lim}}(\operatorname{IgM})=(a / b) \times\left(Q_{\mathrm{alb}}^{2}+b^{2}\right)^{1 / 2}-c
$$

(with $a / b=0.67, b^{2}=120 \times 10^{-6}, c=7.1 \times 10^{-3}$ ). The intrathecally synthesized fraction of IgM, in percentage of total CSF IgM, was calculated as

$$
\mathrm{IF}_{\mathrm{IgM}}=\left[1-Q_{\mathrm{Lim}}(\mathrm{IgM}) / Q_{\mathrm{IgM}}\right] \times 100
$$

(with $Q_{\mathrm{IgM}}=$ measured CSF/serum IgM quotient) (Reiber \& Peter 2001). An $\mathrm{IF}_{\mathrm{IgM}}>0 \%$ indicates intrathecal synthesis and was considered positive. Alternatively, the IgM quotient can be graphically represented in function of $Q_{\text {Alb }}$ (Reiber \& Peter 2001). The reference range of the blood derived IgM fractions in CSF is under the hyperbolic reference curve $Q_{\text {Lim }}(\operatorname{IgM})$. Values above $Q_{\text {Lim }}(\operatorname{IgM})$ represent the intrathecal IgM fractions as percentage of total CSF concentrations, independent of the blood-IgM concentration and blood-CSF barrier function, and can be directly read from the Reiber quotient diagrams, with the $Q_{\text {Lim }}$ as $0 \%$ synthesis.

A modified receiver-operator characteristic (ROC) curve was constructed for estimation of sensitivity and specificity of the LATEX/IgM for intrathecal IgM synthesis (Jacobson 1998).

LATEX/IgM end-titre, cell count and presence of trypanosomes in CSF

The LATEX/IgM test was performed on CSF samples of 937 patients before treatment originating from Equator Province in R.D. Congo (259 samples), Central-West Côte d'Ivoire (104 samples), Arua district, Northern Uganda (205 samples), Southern Sudan (342 samples) and from Central African Republic (27 samples). LATEX/IgM testing on CSF samples from R.D. Congo, Côte d'Ivoire and Uganda was performed at the Institute of Tropical Medicine, samples from Sudan and Central African Republic were tested on the spot. A total of 191 patients had 0-5 cells $/ \mu \mathrm{l}$ and no trypanosomes in CSF, 198 patients had 6-20 cells/ $\mu$ and no trypanosomes in CSF, 51 patients had $\leq 20$ cells/ $\mu$ l and trypanosomes in CSF and 497 patients had $>20$ cells $/ \mu$.

\section{Results}

Intra-assay variability, batch to batch variation and stability of the LATEX/IgM reagent

The end-titres of two CSF samples, tested 20 consecutive times with the same batch of reagent, showed no variation, indicating minimal intra-assay variability. With one sample an end-titre of 8 was obtained 20 times, with the other CSF sample an end-titre of 128 was observed 20 times. The reactivity of seven batches of LATEX/IgM reagent (produced with two different batches of mouse antihuman IgM) with the references showed a maximum difference of one titre step in one reference sample, observed on one occasion, indicating minimal batch to batch variation.

All stored reagents remained monodisperse and the reaction with PBS was always negative when the stability of the reagent was checked. The reagent stored at $4{ }^{\circ} \mathrm{C}$ maintained its original reactivity throughout the experiment as reflected by the end-titres which differed maximally one titre step (Table 1). With the reagent stored at $45{ }^{\circ} \mathrm{C}$, in all samples (R1-R5), differences of at most one titre step were observed, with one exception (R3), which differed two titre steps on one occasion. At day 406, an unexplained drop in end-titre from 3200 to 800 occurred in this sample.

\section{Concordance between CSF end-titre in LATEX/IgM and the IgM concentration}

The CSF end-titres obtained with LATEX/IgM in function of the corresponding IgM concentration in the samples are shown in Figure 1. A parallel increase of end-titre and CSF IgM concentration is observed. Although within each of the 11 end-titre groups, large variations of IgM concentrations can occur, the mean IgM concentrations of these groups differed significantly $\left(P<10^{-3}\right)$.

\section{Intrathecal IgM synthesis and determination of a LATEX/IgM cut-off end-titre}

Using the presence of intrathecal IgM synthesis $\left(\mathrm{IF}_{\mathrm{IgM}}>0 \%\right)$ as the reference, the sensitivity and specificity of LATEX/IgM for intrathecal IgM synthesis were calculated on 289 patients for each cut-off and compared using a modified ROC curve (Figure 2). The best combination of sensitivity and specificity for intrathecal IgM synthesis were obtained at LATEX/IgM cut-off $\geq 8$ (specificity $92.7 \%$, sensitivity $89.4 \%$ ), although at 
V. Lejon et al. IgM quantification in CSF of sleeping sickness patients

Table I End-titres of five reference sera with LATEX/IgM reagent which was stored for up to 938 days at 4 and $37-45^{\circ} \mathrm{C}$

\begin{tabular}{lrrlrlll}
\hline $\begin{array}{l}\text { LATEX/IgM } \\
\text { storage time }\end{array}$ & $\begin{array}{l}\text { Storage } \\
\text { temperature }\end{array}$ & \multicolumn{1}{c}{ R1 } & R2 & R3 & R4 & R5 & PBS \\
\hline 0 days & & 12800 & 6400 & 3200 & 800 & 400 & Negative \\
35 days & $4{ }^{\circ} \mathrm{C}$ & 6400 & 6400 & 3200 & 800 & 400 & Negative \\
& $45^{\circ} \mathrm{C}$ & 6400 & 3200 & 3200 & 800 & 400 & Negative \\
92 days & $4{ }^{\circ} \mathrm{C}$ & 6400 & 6400 & 1600 & 800 & 400 & Negative \\
& $45^{\circ} \mathrm{C}$ & 6400 & 3200 & 1600 & 400 & 400 & Negative \\
183 days & $4{ }^{\circ} \mathrm{C}$ & 12800 & 6400 & 1600 & 800 & 200 & Negative \\
& $45^{\circ} \mathrm{C}$ & 12800 & 6400 & 1600 & 800 & 200 & Negative \\
289 days & $4{ }^{\circ} \mathrm{C}$ & 6400 & 3200 & 3200 & 800 & 400 & Negative \\
& $45^{\circ} \mathrm{C}$ & 6400 & 3200 & 3200 & 800 & 400 & Negative \\
406 days & $4{ }^{\circ} \mathrm{C}$ & 6400 & 3200 & 1600 & 800 & 400 & Negative \\
& $45^{\circ} \mathrm{C}$ & 6400 & 3200 & 800 & 800 & 400 & Negative \\
497 days & $4{ }^{\circ} \mathrm{C}$ & 12800 & 6400 & 3200 & 800 & 400 & Negative \\
& $45^{\circ} \mathrm{C}$ & 12800 & 6400 & 3200 & 800 & 400 & Negative \\
727 days & $4{ }^{\circ} \mathrm{C}$ & 12800 & 6400 & 3200 & 800 & 400 & Negative \\
& $45^{\circ} \mathrm{C}$ & 12800 & 6400 & 3200 & 800 & 400 & Negative \\
938 days & $4{ }^{\circ} \mathrm{C}$ & 6400 & 3200 & 1600 & 800 & 400 & Negative \\
& $45^{\circ} \mathrm{C}$ & 12800 & 3200 & 1600 & 800 & 400 & Negative \\
\hline
\end{tabular}

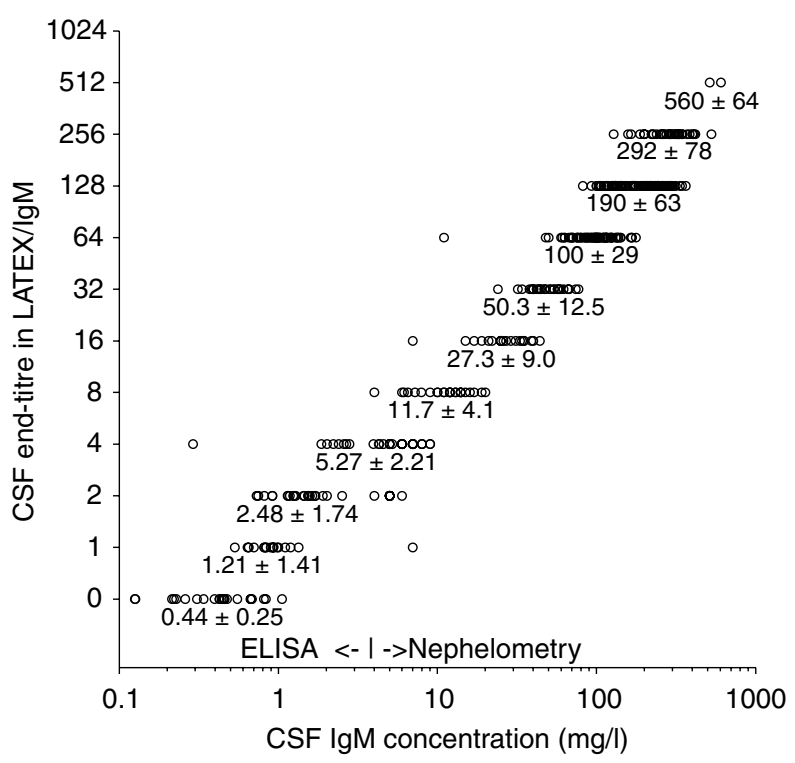

Figure I End-titre in LATEX/IgM of 435 CSF samples in function of the CSF IgM concentration measured by nephelometry (concentrations $>4 \mathrm{mg} / \mathrm{l}$ ) and ELISA (concentrations $<4 \mathrm{mg} / \mathrm{l}$ ). For each end-titre, the mean value \pm standard deviation is indicated.

cut-off $\geq 4$ specificity and sensitivity were still high, 84.1 and $95.4 \%$, respectively. The relationship between $Q_{\mathrm{IgM}}, Q_{\mathrm{Alb}}$ and the LATEX/IgM cut-off end-titre of $\geq 8$ is visualized in a Reiber quotient diagram (Figure 3).

Of the patients with $0-5$ cells $/ \mu 1$ and no trypanosomes in CSF, 7/28 had end-titres $\geq 8$, including all four patients with intrathecal IgM synthesis. Among the patients with

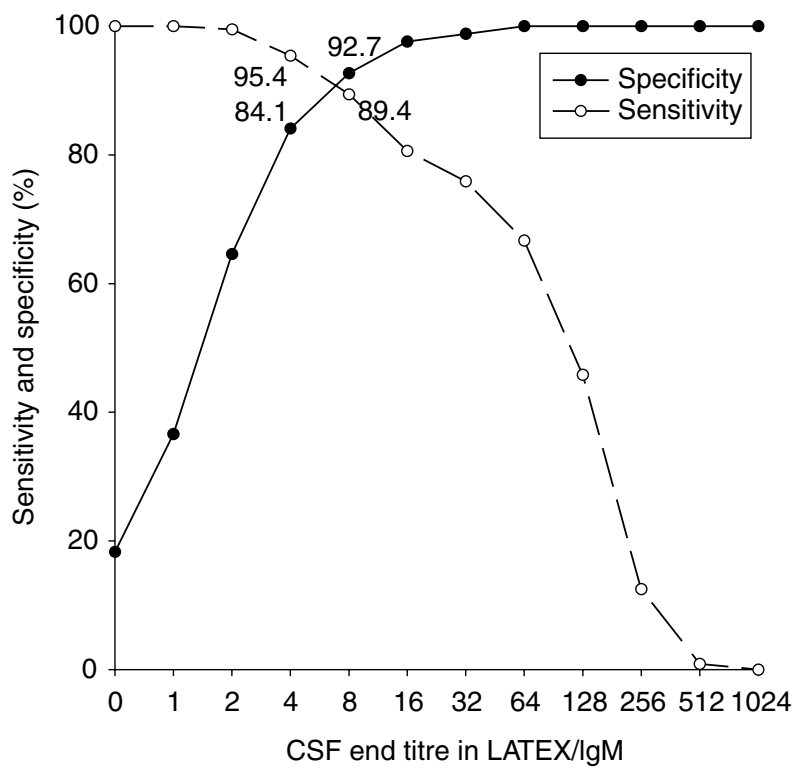

Figure 2 Modified receiver-operator characteristics curve of sensitivity and specificity for intrathecal IgM synthesis as a function of different cut-off LATEX/IgM end-titres.

6-20 cells $/ \mu$ and no trypanosomes in CSF, $15 / 54$ had end-titres $\geq 8$, including $13 / 25$ of the patients with intrathecal IgM synthesis. A total of $16 / 43$ of the patients with $\leq 20$ cells $/ \mu$ land trypanosomes in CSF had end-titres $\geq 8$, including 14/23 with intrathecal IgM synthesis. Of the 173 patients with $>20$ cells $/ \mu$ l, 168 had an end-titre $\geq 8$, including $162 / 164$ of the patients with intrathecal IgM synthesis. 


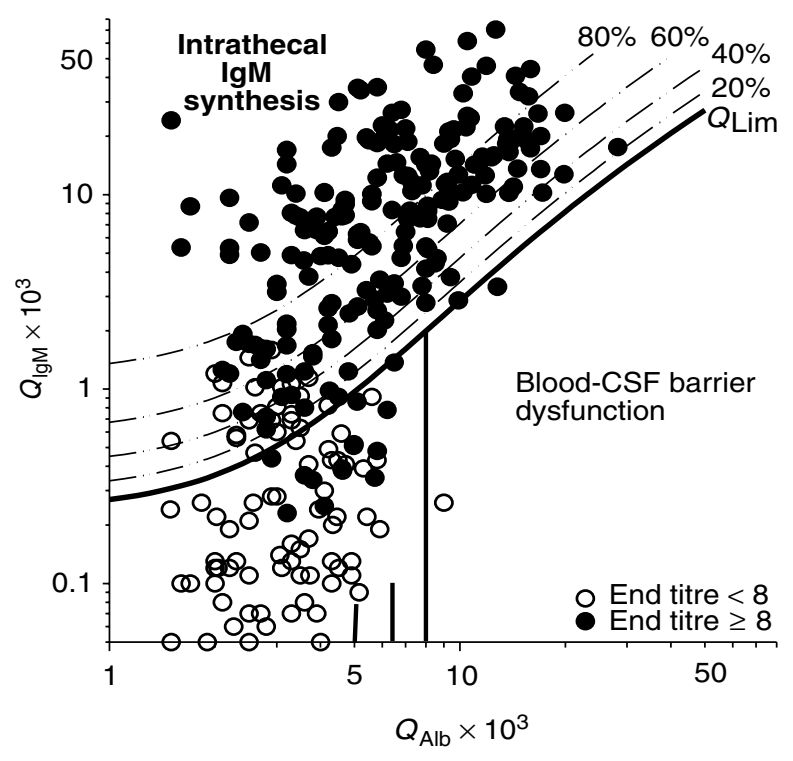

Figure $3 \mathrm{CSF} /$ serum quotient diagram for IgM with hyperbolic graphs (Reiber \& Peter 2001). The normal range of blood-derived IgM fraction in CSF is under the bold hyperbolic line $Q_{\text {Lim. }}$. Values above the $Q_{\mathrm{Lim}}$ line represent intrathecal IgM fractions $\left(\mathrm{IF}_{\mathrm{IgM}}\right)$, as percentage of total CSF concentration. The bold vertical lines indicate the age-dependent upper reference range for normal blood-CSF barrier function. Patients with LATEX/IgM end-titres $<8$ are indicated by open circles, patients with LATEX/IgM endtitres $\geq 8$ by black dots.

LATEX/IgM end-titre compared with CSF cell count and presence of trypanosomes

Using a cut-off value of $\geq 8$, the number of positive and negative samples in a total of 937 T.b. gambiense patients, including the ones discussed above, were determined (Table 2). About $93.2 \%$ of the patients with $>20$ cells $/ \mu \mathrm{l}$ had CSF LATEX/IgM end-titres $\geq 8$. Of the conventional first-stage patients (0-5 cells/ $\mu \mathrm{l}$, trypanosome negative), $11.5 \%$ were positive at this cut-off. Among the secondstage patients with $\leq 20$ cells/ $\mu$ l $(6-20$ cells/ $\mu$ l and trypanosome negative, $0-20$ cells/ $\mu$ l but trypanosome positive) between 32.8 and $39.2 \%$ were positive at cut-off $\geq 8$.

\section{Discussion}

In view of the limitations of the currently used tests, and the importance of accurate diagnosis, first of the disease stage and secondly of possible relapses after treatment, alternative parameters for central nervous system involvement and follow-up in T.b. gambiense sleeping sickness patients are necessary. The massive intrathecal IgM synthesis in sleeping sickness leads to highly increased CSF IgM levels (Bisser et al. 2002). Detection of intrathecal IgM could therefore be replaced by the simple detection of IgM in CSF, which is, however, less accurate. IgM in CSF has been proven to be a marker of interest, but has never been used because of the technical limitations encountered at rural health centres in endemic regions.

Our latex agglutination assay for $\operatorname{IgM}$ quantification of sleeping sickness patients can be applied in the field, as was performed for this study in Sudan and in Central African Republic. The result, the end-titre or highest dilution still causing an agglutination reaction, corresponds well with the total IgM concentration in the sample. The detection limit of LATEX/IgM is around $1 \mathrm{mg} / \mathrm{l}$, which is close to the upper limit for the normal CSF IgM concentration of 0.05-0.8 mg/l in Caucasian individuals (Felgenhauer 1998). Of the 407 CSF samples containing IgM concentrations higher than $0.8 \mathrm{mg} / \mathrm{l}, 99.3 \%$ had a LATEX/IgM end-titre higher or equal to 1. Application of LATEX/IgM for other neurological disorders accompanied by smaller increases in CSF IgM concentrations could therefore be studied. Application of the test for stage determination in T.b. rhodesiense patients remains to be evaluated, although IgM estimations in CSF for determination of meningoencephalitic stage proved to be a valid indicator in T.b. rhodesiense sleeping sickness as in T.b. gambiense disease (Itazi 1981).

Intrathecal IgM synthesis indicates neurological involvement of T.b. gambiense infection (Greenwood \& Whittle 1973; Lejon et al. 1998a; Bisser et al. 2002).

Detection of intrathecal IgM synthesis (Reiber 1998) or of oligoclonal IgM (Sindic et al. 1994) in CSF are, however, not possible in most health centres or hospitals where the disease is endemic, while LATEX/IgM is.

Table 2 Number of positive and negative samples in four groups of T.b. gambiense patients using a cut-off LATEX/IgM CSF end-titre of $\geq 8$

\begin{tabular}{|c|c|c|c|c|}
\hline $\begin{array}{l}\text { LATEX/IgM } \\
\text { end-titre }\end{array}$ & $\begin{array}{l}0-5 \text { cells } / \mu \text { l, no trypanosomes } \\
(n=191)\end{array}$ & $\begin{array}{l}6-20 \text { cells/ } \mu 1, \text { no trypanosomes } \\
(n=198)\end{array}$ & $\begin{array}{l}\leq 20 \text { cells/ } \mu l, \text { trypanosome positive } \\
(n=51)\end{array}$ & $\begin{array}{l}>20 \text { cells } / \mu l \\
(n=497)\end{array}$ \\
\hline LATEX/IgM $<8$ & $169(88.5 \%)$ & $133(67.2 \%)$ & $31(60.8 \%)$ & $34(6.8 \%)$ \\
\hline LATEX/IgM $\geq 8$ & $22(11.5 \%)$ & $65(32.8 \%)$ & $20(39.2 \%)$ & $463(93.2 \%)$ \\
\hline
\end{tabular}


V. Lejon et al. IgM quantification in CSF of sleeping sickness patients

LATEX/IgM end-titres at a cut-off $\geq 8$ show $92.7 \%$ specificity and $89.4 \%$ sensitivity for intrathecal IgM synthesis, reflecting CNS pathology. At this cut-off, the increased serum IgM concentration in sleeping sickness seems to influence the CSF concentration only to a limited extent. But we emphasize that this high cut-off end-titre is only valid for T.b. gambiense sleeping sickness with its high serum IgM concentrations, and that if LATEX/IgM were applied for other neurological diseases, a new, disease-specific cut-off should be determined based on occurrence of intrathecal IgM synthesis.

Of the classical first-stage patients, based on CSF cell count and presence of trypanosomes in the CSF, $11.5 \%$ show an increased $(\geq 8)$ CSF end-titre in LATEX/IgM. More than half of these patients show intrathecal IgM synthesis thus central nervous system involvement and therefore might have relapsed after pentamidine treatment. Unfortunately, details on the outcome of the tested patients after treatment are not available. As a consequence, patients with a normal CSF cell count but with CSF endtitres of $\geq 8$ in LATEX/IgM should be considered at risk for relapse when treated with pentamidine, and followed with special attention.

Among the T.b. gambiense patients with cell counts $\geq 20 \mathrm{cells} / \mu \mathrm{l}$, intrathecal synthesis is observed in $95 \%$ of the patients, confirming that most, if not all of these patients, have CNS involvement and should be treated as such. This was confirmed by the end-titres, which were $\geq 8$ in about $95 \%$ of the patients. Based on these results, application of LATEX/IgM on patients with $>20$ cells/ $\mu \mathrm{l}$ for decision on second-stage treatment seems redundant.

In the early second-stage groups $(6-20 \mathrm{cells} / \mu \mathrm{l}$ and trypanosome negative, $\leq 20$ cells with trypanosomes in CSF) about $34 \%$ of the patients have a CSF LATEX/IgM end-titre of $\geq 8$, of which 87 and $94 \%$ also had intrathecal IgM synthesis. Current practice in Angola and Côte d'Ivoire is to treat patients with cell counts up to 20 cells $/ \mu \mathrm{l}$ and in whom no trypanosome can be detected in CSF, with pentamidine (Doua et al. 1996; Stanghellini \& Josenando 2001). The success of this approach is poorly documented. A recent clinical trial showed that $43 \%$ of such patients relapse after pentamidine treatment (D. Legros, personal communication). As discussed above, patients with endtitres $\geq 8$ are to be considered at high risk of relapse if treated with Pentamidine.

Based on the results obtained with first and early secondstage patients, further studies should concentrate on the relationship between the LATEX/IgM end-titres, presence of intrathecal IgM synthesis and occurrence of treatment failure.

In addition to its use for stage determination, the use of LATEX/IgM for follow-up after treatment should be investigated based on evidence that relapses are characterized by a strong rise in CSF IgM (Whittle et al. 1977). The minimal batch to batch variation and the high stability of the LATEX/IgM reagent open perspectives for its use for follow-up of sleeping sickness patients. But at present there are not enough data on the evolution of CSF end-titres in LATEX/IgM during follow-up.

\section{Acknowledgements}

This investigation received financial support from the Belgian Directorate General for International Co-operation, the European Union and Médecins Sans Frontières.

\section{References}

Bisser S, Bouteille B, Sarda J et al. (1997) Apport des examens biochimiques dans le diagnostic de la phase nerveuse de la trypanosomose humaine. Bulletin de la Société de Pathologie Exotique et de Ses Filiales 90, 321-326.

Bisser S, Lejon V, Preux PM et al. (2002) Blood-cerebrospinal fluid barrier and intrathecal immunoglobulins compared to field diagnosis of central nervous system involvement in sleeping sickness. Journal of the Neurological Sciences 193, 127-135.

Doua F, Miezan TW, Sanon SR, Boa YF \& Baltz T (1996) The efficacy of pentamidine in the treatment of early-late stage Trypanosoma brucei gambiense trypanosomiasis. American Journal of Tropical Medicine and Hygiene 55, 586-588.

Felgenhauer K (1998) Laboratory diagnosis of neurological diseases. In: Clinical Laboratory Diagnostics (ed L Thomas) TH Books, Frankfurt, pp. 1308-1326.

Greenwood BM \& Whittle HC (1973) Cerebrospinal-fluid IgM in patients with sleeping-sickness. Lancet 2, 525-527.

Itazi OK (1981) Radial Immunodiffusion as a Diagnostic Test for African Human Trypanosomiasis in Cases with Neurological Involvement. International Scientific Council for Trypanosomiasis Research and Control. Report of the 17th meeting, Arusha, 101-106.

Jacobson RH (1998) Validation of serological assays for diagnosis of infectious diseases. Revue Scientifique et Technique Office International Des Epizooties 17, 469-486.

Lejon V, Büscher P, Magnus E et al. (1998a) A semi-quantitative ELISA for detection of Trypanosoma brucei gambiense specific antibodies in serum and cerebrospinal fluid of sleeping sickness patients. Acta Tropica 69, 151-164.

Lejon V, Büscher P, Sema NH, Magnus E \& Van Meirvenne N (1998b) Human African Trypanosomiasis: a latex agglutination field test for quantifying IgM in cerebrospinal fluid. Bulletin of the World Health Organization 76, 553-558.

Magnus E, Vervoort T \& Van Meirvenne N (1978) A cardagglutination test with stained trypanosomes (CATT) for the serological diagnosis of T.b.gambiense trypanosomiasis. Annales de la Société Belge de Médecine Tropicale 58, 169-176. 


\section{Lejon et al. IgM quantification in CSF of sleeping sickness patients}

Mattern P (1967) Etude du taux de gamma-globuline dans le liquide cephalo-rachidien. Septième Conférence Technique OCCGE, Mars, 1053-1056.

Mattern P (1968) Etat actuel et résultats des techniques immunologiques utilisées à l'Institut Pasteur de Dakar pour le diagnostic et l'étude de la trypanosomiase humaine africaine. Bulletin of the World Health Organization 38, 1-8.

Pagano M \& Gauvreau K (2000) Analysis of variance. In: Principles of Biostatistics (eds C Crockett, S Atwal, T Novack) Duxburry Press, Pacific Grove, pp. 285-301.

Reiber H (1998) Cerebrospinal fluid - physiology, analysis and interpretation of protein patterns for diagnosis of neurological diseases. Multiple Sclerosis 4, 99-107.

Reiber H \& Felgenhauer K (1987) Protein transfer at the blood cerebrospinal fluid barrier and the quantitation of the humoral immune response within the central nervous system. Clinica Chimica Acta 163, 319-328.

Reiber H \& Peter JB (2001) Cerebrospinal fluid analysis: diseaserelated data patterns and evaluation programs. Journal of the Neurological Sciences 184, 101-122.

Sindic CJM, Monteyne P \& Laterre EC (1994) Occurrence of oligoclonal IgM bands in the cerebrospinal fluid of neurological patients: an immunoaffinity-mediated capillary blot study. Journal of the Neurological Sciences 124, 215-219.

Stanghellini A \& Josenando T (2001) The situation of sleeping sickness in Angola: a calamity. Tropical Medicine and International Health 6, 330-334.

Van Meirvenne N (1999) Biological diagnosis of human African trypanosomiasis. In: Progress in Human African Trypanosomiasis, Sleeping Sickness (eds M Dumas, B Bouteille \& A Buguet). Springer, Paris, pp. 235-252.

Van Nieuwenhove S (1999) Present strategies in the treatment of human African trypanosomiasis. In: Progress in Human African Trypanosomiasis, Sleeping Sickness (eds M Dumas, B Bouteille \& A Buguet). Springer, Paris, pp. 253-281.

Whittle HC, Greenwood BM, Bidwell DE, Bartlett A \& Voller A (1977) IgM and antibody measurement in the diagnosis and management of Gambian trypanosomiasis. American Journal of Tropical Medicine and Hygiene 26, 1129-1135.

WHO (1998) Control and surveillance of African trypanosomiasis. WHO Technical Report Series 881, 1-113. 